\title{
Modern Revolutions and Beyond
}

An Interview with John Dunn

Benjamin Abrams

Abstract: John Dunn, FBA, is emeritus professor of political theory at King's College, University of Cambridge. His work on revolution began in 1972 with the publication of his landmark volume, Modern Revolutions: An Introduction to the Analysis of a Political Phenomenon. A second edition was published in 1989, and the volume has since been translated into several foreign languages. Alongside revolution, Dunn's thought has examined questions of regime collapse, reconstruction, the political trajectories of modern states, and the emergence and significance of democracy. His work lies at the intersection of history, political theory, and sociology. In the interview, Dunn offers a categorization of revolution as a distinctly bounded historical phenomenon which has not persisted into the twenty-first century. "The Epoch of Revolution," he argues, begins with 1789 and had definitively ended by 1989. After the epoch of revolution, Dunn argues, we now confront a more enduring and generic phenomenon: regime collapse.

Keywords: democracy, modern revolutions, political theory, regime collapse, revolution

Almost anyone writing on the subject of revolution today will remember having read John Dunn's Modern Revolutions $(1972,1989)$. The book, published before Dunn was appointed a lecturer at Cambridge, went on to meet with immense success, and remains perhaps the most impactful piece of political theory published on the topic in the last fifty years. Though Modern Revolutions itself only received one formal English-language update, in 1989, Dunn's theory of 
revolution has continued to evolve, as alluded to in fragmentary portions of his later work, occasional essays, and introductions to the work's many translated editions. Most crucially, as only a few of those who have read Dunn's work will know, Dunn taught on the subject uninterrupted for more than thirty years. On the forty-fifth anniversary of the work, I thought it would be instructive and useful for the wide variety of scholars across disciplines who have engaged with or relied upon Dunn's work to see a picture of his thought today. In addition to this interview, I would encourage readers to examine Dunn's essay "Understanding Revolution," which was published in the edited volume Revolution in the Making of the Modern World (2008), and his introduction to the Spanish edition of Modern Revolutions (2014).

In the interview, Dunn defends a categorization of revolution as a distinctly bounded historical phenomenon that has not persisted into the twenty-first century. "The Epoch of Revolution," he argues, begins with 1789 and had definitively ended by 1989. During this period, revolutions were characterized by a cast list of professional revolutionaries, offering an "intellectually plausible horizon of collective hope in something completely different." They marked "not just the collapse of the regime but the subsequent construction of an unmistakably new kind of regime,” Dunn argues.

For Dunn, revolutions are built on this hope, and this hope comes to justify often incredibly destructive political processes. Explaining how thinking about revolution over the past fifty years has changed his views on the topic, Dunn concludes that "revolutions are actually a particularly politically dangerous sort of process." For Dunn, revolutions are, at their core, civil wars. Like all wars, they are particularly hazardous, posing enormous risks to societies and those who live in them: "Revolution has not, in the long run, turned out to be any more politically benign than a sort of feudal war," Dunn noted. 
Today, however, Dunn's Epoch of Revolution has passed. After this epoch, we now confront a more enduring and generic phenomenon: regime collapse. "Regime collapse doesn't have the same kind of homogeneity to it [as revolution]," Dunn explains, "because apart from anything else regimes differ a great deal in their character across time and space." Cases of regime collapse, within which Dunn includes the post-Soviet orange (or "color") revolutions as well as the 2011 “Arab Spring,” lack revolution's core characteristics_-particularly a kind of regime reconstruction which was contiguous with the goals of those who pursued the regime's collapse. But we should not bemoan the loss of revolution in the present day, either politically or academically, Dunn argues. "'Regime collapse' is a term which retains its capacity to focus helpfully, and provides a space within which it's possible to think instructively after revolution," he explained. In fact, "being hypnotized by revolution is a very very considerable impediment for political comprehension.” For Dunn, today's problems are more fundamentally existential, and what is needed is not revolution, but understanding.

The rest of this article comprises an account of my interview with Dunn. After a week of preparation, during which we decided which questions to focus on and set a format for the interview, we spent around two hours in discussion. The material as it is included here comes from an intelligent verbatim transcription of our conversation as it pertained to Dunn's work, with additional edits for clarity.

\section{Revolutions since 1972}

Benjamin Abrams (BA): When you first offered your analysis of modern revolutions, we were bearing witness to a kind of rolling wave of them throughout the first two thirds of the twentieth century. Since then, we've had some subsequent waves, albeit in much tighter time windows, 
and much of what you said in 1972 appears to hold up rather well, even forty-five years later. With this in mind, what would you say most clearly distinguishes the kinds of revolution which have come more recently from the kind which you analyzed in 1972?

\section{A “Horizon of Political Hope"}

John Dunn (JD): When I wrote that book I was trying to think about revolution as a competitor in defining the horizon of political hope for any society. I wasn't trying to think about it just as a particular political crisis in a particular society.

I think the key difference is that in 1972 it still made sense to think about revolution politically on terms set by what happened in Russia in 1917. It's definitely not very helpful to think about the revolutions that have occurred since 1972 in response to or based on the Russian revolution-it simply does not work at all.

If you look at what's happened since 1972, I suppose the most important example that people think of as a revolution is what took place in Iran in 1979. It was in some ways rather like what took place in Paris in 1789. In other ways, of course, it didn't fit at all with the picture of a political future which ran forwards from 1789. That's one reason for thinking that you can't wrap the candidates for revolution that have taken place since 1972 inside the same interpretative structure with any plausibility.

Of course, the weaker the structure that you wrap them in, the more plausible candidates there are. I was, in some sense, trying to see how strong a political interpretation of the nature of revolution it made any intellectual sense to entertain.

If you run forwards from the Iranian Revolution, two remaining episodes are the process of collapse (and in some cases recollapse) of the Soviet Union and the states left behind from it. 
You can think of those as just regime collapse: there were many regime collapses before 1789 . For as long as there have been regimes, there has been regime collapse. Regime collapse doesn't have the same kind of homogeneity to it [as revolution] — because apart from anything else, regimes differ a great deal in their character across time and space.

You could say that there was a sort of candidate for hope at the time, which was the global liberal order, but that was never a very promising candidate as potentially generative of a transformationally decisive guarantee of the future of a society — which is very much the aim with which, after Paris 1789 , people were trying to enact revolution.

\section{Professional Revolutionaries with Transformative Goals}

JD: I put a lot of weight on the idea of the role of a professional revolutionary. They defined the political character of revolutions - not by imposing preferences on what happened, but by modifying, very drastically, the political dynamics of what was historically in question. I don't think that has actually survived [today].

There are some people who are carrying on regardless, but it doesn't matter much that they're carrying on regardless, and insofar as it ever does matter, it doesn't matter because it's reasonable to anticipate that there won't be a re-enactment of what took place in Russia in October 1917. I think that picture of revolution doesn't make sense anymore. I don't think of the [early 2000s] "orange revolutions"1 as being in any way like that, except insofar as they're instances of regime collapse.

The key point that I wanted to make about what revolutions had turned out to be in the twentieth century, obviously some more than others, was not just the collapse of the regime but the subsequent construction of an unmistakably new kind of regime which actually had the 
capacity to persist for a bit. It doesn't make sense to think of the orange revolutions in those terms: they weren't reconstructive in any dramatic way, and they certainly weren't intended to define the pathway of the future — even by the people who made them.

The second large wave of revolutionary aspiration was what was called for a while the "Arab Spring. That was a rather dramatic international political process, but it was one within a certain type of society - a society defined by the predominance of one particular religion. You had an abundance of regime collapse, but you didn't get a lot of regime reconstruction of a kind that lasted for more than a quarter of an hour. In some of the instances, the result was very protracted and extremely comprehensive political chaos, and therefore social and economic chaos too: the ruin of societies.

Only in the case of Tunisia was what took place the collapse of a regime and, arguably, the politically orchestrated emergence of a new regime which might actually turn out to be the governmental and social and economic structure of the society in question for quite a long time ahead. You never can tell how long, but you never could. If you look at the revolutions that I was considering in the first sixty-plus years of the twentieth century, not very many of those are still there and the ones that are still there vary a lot in how durable they look.

BA: Although, in this post-millennial context, we might be seeing a great many revolutions, we're seeing far fewer successful ones. On the basis of what you said in Modern Revolutions, one would suppose that this would be down to a poor supply of competent revolutionary leaders, despite regime fragility. Would this be your interpretation today?

JD: Well, I see the supply of leadership as being a consequence of a number of different sorts of 
things, so I don't think of it as being a sort of structurally guaranteed feature of societies for revolution. I think of it more as a fairly dynamic political tradition - the tradition of political action - than I do as a structural consequence of regime fragility.

\section{The Disappearance of Collective Hope}

JD: What is incredibly important in thinking about revolution today is the disappearance of an intellectually plausible horizon of collective hope in something completely different. A lot of the political force of revolution in the twentieth century came from its imaginative dynamic. This, in my view, came from the very deep and very widely distributed revulsion at the experience of industrializing capitalism, which was a global experience tendentially. It did not reach everywhere in the twentieth century, but it was moving across the globe pretty purposefully throughout, so there was something spreading at the time. It spread that transformative hope with it partly because that was a reasonable way of looking at what was happening, and that's what people wanted to believe was happening, but also partly because it often looked as if that actually was what was happening.

If you ask: "Well, where did that hope go?" Obviously, the impulse to hope doesn't go. It can be, and is, revived in people all the time. But there isn't anything comparable to the degree of intellectual articulation of hope - and the apparently rational practical interpretation of the basis for hope - that there was in the first three quarters of the twentieth century.

I think of the story [of revolution] as being inseparably connected to the history of socialism: ${ }^{2}$ the hope that society (especially an egalitarian society) had the intrinsic capacity to re-impose its own terms on a process of economic structuring which seems - and indeed was, and is - utterly inhuman. If you think of that as a type of political hope, a lot of political 
quarrelling across the twentieth century has been about what exactly the shape of the hope should be taken to be: how to hope in an intellectually accurate way which captured the real causalities.

In the period up to not very long before I wrote the book, there was still considerable global impetus to interpret history in a way which saw socialism as the shape of future promise for the human population of the world. I don't believe that is actually intellectually practicable any longer. I don't think there's any way of doing that. You can carry on listening [to these kinds of claims], but that just tells you that old speech patterns die hard, but it doesn't tell you at all about what might actually happen.

It wasn't unreasonable for people to think politically within that space and for people that were very clever, and interested in getting their thinking as causally accurate as they could, to think in those terms. I don't think people who were trying to do that can really think in those terms any longer. They can continue to speak in those terms, and obviously in some important historical settings they still do speak in those terms: whatever the [Chinese] Politburo say to one another, they can't speak to their citizen underlings in terms which profane socialism. They can't say: "Unfortunately, it's turned out that socialism is an illusion and what you're going to have is capitalism and the question is whether it can be given more attractive Chinese characteristics than we've so far managed to pull off, and you should hope for the best for us because that's the best for you!"

\section{The Revolutionary Potential of the "Information Revolution"}

BA: You remarked (1989: 5) that the industrial revolution "undoubtedly made a number of very important differences ... and nowhere has it made more of an impact than on the practice of 
revolution." Would you say the same about the "information revolution" today?

JD: No, I wouldn't. I do think that the information revolution has altered political dynamics a lot. It has done so as much in societies that haven't as yet undergone anything that you could possibly think of as a revolution as in societies that have. I don't think that it has shown a potential for the reconstruction of a regime of a different kind: an imagination of fairly drastic political momentum in the direction of power. I just don't think there's any reason for it to do that. As the sort of process that it is, I don't see how it could do that. It certainly hasn't shown any sign of doing that so far.

It makes a lot of difference whether or not a regime which is facing immediate challenge from its lower orders is able to contain the challenge. But of course it also means that regimes which are not as yet seriously challenged by their lower orders, and which are pretty politically solid from many angles, can impose much tighter control than they've ever been able to before. So I think it's had a very ambivalent political impact really.

\section{Dunn's Further Thought after Modern Revolutions}

\section{Revolution as a Social Event}

BA: One thing that people may not know is that you initially envisaged Modern Revolutions as a didactic text, and that for your whole time at Cambridge much of your activity had been devoted to teaching a course on revolutions, which arguably has been the pre- and post-history of what you were trying to do in Modern Revolutions. I was wondering if you'd be able to talk a little bit more about how your thought on the subject has developed since, as it's not always written in books as much as it may be impressed in the minds of students and now colleagues. 
JD: I taught the course entirely on my own initially, because there wasn't anybody else teaching politics that was employed by the university, but over time I taught it with a number of different colleagues, all of whom were much more stably and determinately on the Left. They weren't all in the same place as I was, but I taught to a great degree through seminars with them —a varying cast of them - and we tried to explore the relative cogency of the political judgment of the principal historical actors in the revolutions that we thought about. Over time, because I went on doing it for much longer than anyone else, I altered my judgment of those quite a bit, and I ended up much more confident about how to understand why revolutions do occur and what their likelier outcomes are.

The main thing I came to focus on was the need to recognize that, the more the 1789 conceptualization of what a revolution is applies in the political crisis of a particular society, the more it will turn out to be the case that what is occurring in a society is a kind of civil war and that the outcome will be decided the way wars are decided. This is in a sort of struggle which doesn't actually track the structures of societies in any steady way. It's affected by the structures of societies, but it's a very distinctive activity. I thought of what a revolution really was as a particularly intense form of political conflict which always was incipiently military in character. That's what I mean by war: the question of killing other people; who is going to kill whom; how many were going to need to be killed before there was a clear victor; and who was to be the victor.

Those are the sorts of questions which define wars, and what revolutions are (unfortunately) are wars, so the more you think of them as transformative vehicles of collective hope, the more you have to recognize that it's actually a very very dodgy business putting your collective hope as a society into what's going to happen in a war. It's not a hope-supportive 
process, war. If the less-bad side wins it's not at all a bad thing that there was a war, it's better than simply the worse side winning in a walkover, but it's not a good kind of process from a human point of view. It's not got a very definite and enduring advantage to it, and it has very definite and very enduring disadvantages even for those who don't get killed or wounded in it.

I altered my picture of what a revolution was from what was originally_it's fair to saya somewhat romantic and theatrical picture. It was a picture much encouraged by the literature of political sympathy with revolution. Revolution has some of that in it. As, of course, do wars. In wars, some people behave extremely impressively, but that doesn't mean to say that you want to think of wars as occasions in which it's particularly easy for the right kind of person to participate to great personal advantage. I don't think that revolutions are like that at all, and I think it's a very profound political error to think that they stand any chance of being so.

When I began to teach about revolution, I was extremely open-minded about the balance of political benefit and cost in the revolutionary tradition. I have to say that over the decades I definitely turned more and more resolutely against it. This is not because I thought that revolutions don't sometimes have very beneficial consequences in some ways, but because I don't think they are at all a benign type of political process. If you think of politics the way Lenin did, which I think is definitely part of the truth about politics, you have to recognize that revolutions are actually a particularly politically dangerous sort of process. The more it's a question of who is going to get their way, the less good it is that the means of their doing so are always converging on murdering other people in large quantities. That just isn't a good way. Revolution has not, in the long run, turned out to be any more politically benign than a sort of feudal war.

BA: This brings us nicely onto some questions about the study of revolution more generally. 
You once described much of general theorizing about revolution-particularly functionalist and Marxist approaches - as likely to "suppress the entire point of revolution as a unique type of social event." I was wondering what, to your mind, was the uniqueness of such events and how we might best capture it.

JD: This does connect up directly with what's different now from what was so then. At that point, revolutions were often entered into by important elements of their "cast list" on a basis of very high hope. You could see the altitude of the hope from different angles. For some, it looked like high hope of dramatic personal advancement; politics always has people like that in ample supply. To others, it looked more like a program of collective salvation. I think that you can't take that element out of the revolutions of the first three-fifths of the twentieth century and actually understand what happened, or why a lot of that happened. That's what I mean, really, about the view that the revolutions between 1789 and 1989 were different from what's happened since. I think the really interesting question about the future of revolution isn't whether the term will stick around, or whether people will look at regime collapses more optimistically than there's good reason to look at them for a bit because of the history of revolution in the twentieth century. The really interesting question is whether there are going to be coincidences of processes of regime collapse, with processes of social and political and economic reconstruction, and the aftermath of regime collapse which have some sort of collective, imaginative, teleological impetus to them. If you think of revolutions as in part mimetic from 1789 onward, what has disappeared from the record was a picture of revolution which combined the theatricality with imagery of collective transformation which had some real existential credibility that a lot of people might see and feel at the same time - and go on seeing and feeling for quite a 
long time even under the necessarily pretty discouraging circumstances of revolution. I don't see anything like that which has appeared since. I don't think that's what happened in Tehran in 1979, and it certainly wasn't what happened in Tunis or Cairo, or Damascus or Benghazi in 2011.

\section{Studying Revolution and Regime Collapse}

BA: Much of your work after Modern Revolutions has made a great deal of reference to the work of Theda Skocpol. You have some quite strong compliments for it, as well as some critiques. I was wondering about how you see the relation between your work and her work, and whether you think the study of revolution has made much progress since.

JD: I don't really believe that a lot of progress has been made in thinking about revolution since Skocpol's book (1979). I don't mean that I think nobody's said anything true and instructive about it, but I don't think that anyone since her has increased the intellectual repertoire for understanding revolution in at all an effective way. A lot of people have said a lot of things about it, and some of the people who have worked on it are people of considerable ability. There have been some very interesting books by historians of particular revolutions, and one or two which were rather wider in their scope: Arno Mayer's book The Furies (2000) is rather an important book for understanding revolutions. It could have kitted you up advantageously for Syria before that really got loose, compared with anything from a sociologist or area studies person on the subject.

BA: This brings us to the question of what is to be done, at least academically, to rehabilitate and 
further the study of revolution. Given that you consider Skocpol (1979) to have made the most recent serious and important contribution, it would be high time for another, or at least for someone aspiring to do something similar. So I was wondering whether you thought there were any particularly good questions or unresolved issues that were important to address today.

JD: I would think from the point of view of academic aspiration, the two really important things are to see that what did happen between 1789 and 1989 (just because it's a convenient way of bracketing it) is a single historical arc and to understand that the very drastic effect it had on world history doesn't mean that the arc is going to recommence. This lets you understand what did happen in that arc in a way that is accurate to the phenomena that occur along it. I just think it's not going to work to think of revolution as one topic anymore. The reason for thinking of it as a topic at all, the reason for thinking of the word revolution as referring to something distinctive and very important is that arc. You can't take the impact of that arc out of the word; it's impacted it in a permanent way now. If you think about revolution within that arc, you are actually thinking about a political phenomenon which has a definite history [even if] some aspects of that obviously run forward beyond the arc.

Along that arc, the idea is this: an old way of living together collectively will collapse; the collapse might be very significantly accelerated by acting in particular ways; and the consequences of this collapse will be the creation of something new, unquestionably superior, and potentially very protracted. I don't think that this expectation makes any sense when projected into the future.

BA: I'm getting a sense in your response here that the age of "modern revolutions" is over. You 
seem to be using the term "regime collapse" a lot to refer to the post-soviet "color" or "orange" revolutions, as well as the Arab Spring that came after them. Would you say that, in your understanding, revolution "runs out" by 1989 and that what many of us are still calling revolution bears greater resemblance to what you call regime collapse?

JD: Yes, I would. "Regime collapse" is a term which retains its capacity to focus helpfully, and provides a space within which it's possible to think instructively after "revolution," looking forward, has rather lost its capacity to do so. Whatever you want to call them, "states," "regimes," "societies," "nations," "countries," as determinately formatted units can collapse, and will go on doing so. It's really important for the people whose lives are lived inside them that that's so. The chances of their doing so will go on being a very important question to think about. What created the imagery [of revolution] in the first place was, to quite a considerable degree, the completeness, speed and the degree of surprise prompted by the collapse. I think it does make sense to think about the process by which regimes collapse as having some degree of commonality, a sort of political logic. I think it makes sense to think of all regimes, always in terms of [the following questions]: How vulnerable are they? What can wound them? What resources do they have for survival, and what are the internal threats to their doing so? If you look at them that way, I think that's a perfectly suitable general approach in political sociology. It could even happen to the United States of America, the paradigm of a regime which has escaped from history into an eternally guaranteed future. If you doubt that it could, just keep watching.

If you think of all regimes that way, it [regime collapse] is a central question about the nature of collective political life in modern states: how fragile their regimes are; what does really 
threaten them with the possibility of collapse; and therefore which of them are actually threatened with the possibility of collapse at any particular time. It certainly makes sense for the people at the top of the regimes, the "regime people," and for people within imaginative sight of them to ask [themselves]: "Under what circumstances could this collapse?" That question is going to go on for as long as there are regimes, so I think it's interesting to study that. The interest is not confined to people in academic life; it's studied intensively all the time within the security apparatuses of states, and it sporadically comes to the attention of the political class as a real issue. Regimes have slightly imaginatively broader "specialists" in that subject in varying numbers depending on how threatened they feel by the question. I think it's intellectually interesting and very politically instructive to think about those things from an academic angle, and a good angle from which for academics to talk politically to their fellow citizens.

I don't think there's exactly a terrific range of intellectual instruments which we've accumulated for doing that in a very powerful way, but I think it's always quite a good question, and if you spend a lot of time thinking about it in a lot of instances, your capacity to think about it in a new instance will be significantly improved if you let it be. If you have to code your achievements in a supposedly authoritarian discourse, that's not so likely to come about.

BA: Among the sociological and political science communities, there have been recent attempts to "roll up" social movements, revolutions, and other forms of political protest into the realm of “contentious politics" (McAdam et al. 2001). Despite the self-professed failure of the project to establish a discipline (McAdam and Tarrow 2011), this has become the reality of much research on revolution within the social sciences. Do you think this step was wholly mistaken, or are there benefits to it as well? 
JD: Well, I think all politics is contentious, and will remain so until the end of human time. So I don't think it's a very good differentiator. I don't know how you'd find uncontentious politics.

I don't think it's a candidate for defining a domain of inquiry, [but] you can use it as a descriptive motif. You could say that insofar as there have been revolutions and insofar as there will be revolutions again in the future, they will certainly be instances of particularly contentious politics: very angry and purposefully mutually harmful politics. That's quite important because it means that the idea that revolution is a rousingly and reliably good thing doesn't really fit with that kind of way of characterizing it or identifying it.

I think it doesn't help to think of revolutions as being instances of something much more general. If you want to think of them that way, they're bound to be instances of something very much more general, but recognizing that isn't very likely to be able to help you understand them very well. If you have any interest in revolutions, rather than the general propensity of human beings to find themselves at odds with each other, then I think you won't want to homogenize the subject matter and stretch it much further; you'll want to try and see how to get any kind of grip at all on the bit that you were originally interested in.

\section{The Epoch of Revolution}

BA: On the matter of the other section of your work, notably democracy. You've devoted a great amount of energy to democracy, and a great amount of energy to revolution, not just in your academic work but also in your teaching. Occasionally in your work, there are hints at an intersection between these two areas of focus: between revolution and democracy. I was wondering if you could expand on this. 
JD: Well, I think that what I call "The Epoch of Revolution" was an epoch in which the hope was that the effect of regime collapse would be very profoundly and very durably democratizing. The horizon of aspiration of revolution and democracy were pretty much the same. As a practical political process, democratization is one which occurs always in a very resistant medium, and it gets only a very limited distance, because there are things which are obstructing it effectively. One way of seeing what defines the epoch of revolution is to see it as an epoch in which the hope to democratize and the hope to realize a revolution are more or less the same- that's to say they're thought of as very tightly internally [and] causally connected. The historical experience of revolution in that epoch was that, unfortunately, it's not true. The effect of revolution is not to democratize. Revolution may remove the privileges from previously privileged groups, but it won't eliminate privileging. It will re-privilege other groups, and it certainly will not have the general effect of raising the degree of personal freedom of a whole population into an indefinite future. It's never had that effect, and I don't think it's a type of political process for which it was ever reasonable to expect to have that effect. I don't mean it was absurd for it to have that effect, but that the more you thought about it, the clearer it would always have been that actually it's not likely to have that effect.

If you read Burke' Reflections on the Revolutions in France (one of the most powerful interpretative works about revolution), [you will see that] Burke actually explains quite well why that is likely to be so, and he's certainly better on the fundamental political mechanisms than the people who have thought their way through it subsequently on the Left.

\section{Revolutionary Vanguards in the Epoch of Revolution and Today}


BA: Your theoretical approach to revolution has at least to some extent a notably Leninist or vanguardist flavor in how you understand modern revolutions. Would you say that's a fair characterization of how you see revolutions, as having some kind of revolutionary vanguard component?

JD: The series of political phases or episodes within what I call "The Epoch of Revolution" do, after 1789 , pick up obviously consequential characters in the cast list who were partisans of and would be performers in revolution. After the French Revolution came to an end, there went on being such people, and what they did went on potentially having really large-scale consequences for a long time. It's not clear to me that anyone operating under that inspiration today is still likely to have any significant consequences. Obviously, political actors who participate in regime collapse and take over in the aftermath will have big political consequences, but it won't be because they're revolutionaries, it will be because they were in a position to take over afterward and they had the political skills and the political luck to be able to do so. I don't think you can think about the consequences they have helpfully through the category of revolution. It is very important that the people who have taken over after those [so-called] "revolutions" were in no case people who had thought of themselves as revolutionaries before the "revolutions," and that no one else would be likely to think of them as that either, afterward.

BA: You identify the revolutions of the twentieth century as having often had an at least nominally Marxist flavor. The past three decades of revolutions have appeared to be ideologically liberal in character, and today's revolutionary circles seem much more engaged with anarchist theory. Has the ideological bent of more "liberal" attempts at revolution altered 
them notably, and would you venture [to say] that today's embryonic anarchistic efforts at revolt will have particular distinguishing characteristics?

JD: Those are very different sorts of questions. In the case of "liberal revolutions," if you want to think of them as being that way: as I've already suggested, I don't think of those as being much of a success from any point of view. If I were asked if it is preferable to be a citizen of Ukraine in its present dodgy position than it was [sic] to be a Ukrainian citizen of the USSR, I would say "yes, it certainly is.” It was really bad being a citizen of the USSR (particularly toward the end), and there was no chance of it getting better. But, I don't think that it's reasonable to expect the collapse of a regime in any setting to have reliably liberal consequences. I think the process of regime collapse is inimical to purely liberal consequences. Sometimes there may be some liberal elements of what appears afterward, but they don't appear in a firmly mutually supporting guise. They appear as purposes of some political actors, so they play some sort of role in the continuing development and consequences of state policy. They're not a systemic shift of the kind which you want to call liberal. I don't actually think of those as being revolutions in an instructive sense. I think it's an unfortunate persistence of naming.

On the potential of the anarchist stuff, it goes back to the quarrel between Marx and Bakunin about whether the idea of putting an authority structure onto the revolutionary process before it had actually begun at a particular place and time was a good idea or not. I think within that quarrel both sides had some good lines and both sides had some very considerable weaknesses. The authoritarian element in the way Marx thought politically certainly came through in the longer run with what happened in Russia and is still happening in China, but I don't think that Bakunin's way of looking at what societies are and how they operate was very 
discerning; I don't think he understood much about it. He certainly didn't have a picture with anything like the same sort of cognitive force [as Marx] of what was shaping human collective life. It isn't just that people operating with Marx on their banners won politically in Russia and China and nobody's ever won with Bakunin, it's that there was more to their victory than just their winning. There was a way of understanding the possibilities of collective life over time and what actually shapes it. It was a much deeper movement politically.

\section{Closing Thoughts}

BA: Is there anything that you would want to say or offer to the academic community thinking about revolution, protest, political action, or contention?

JD: I feel that I've got an enormous amount out of thinking about revolution over the period of time that I have been thinking about it. It's around fifty years now, I suppose. I think that what I've got out of it is potentially valuable for thinking about politics ${ }^{3}$ quite generally, but I don't think that you could only get what I have got out of it by having done that. I would like to think that the way that I try to teach people about how to understand politics has been partly generated by it, but it doesn't require anybody who is trying to benefit from it to take a comparable route. I would more think of it from an educational point of view as being a very, very, very long detour to places you could get to quicker if you knew where they were.

I don't think I would want to say there's something particularly important about revolution which they should all necessarily consider. I think that being hypnotized by revolution is a very very considerable impediment to political comprehension. It's obstructive of it. It isn't just distracting; by now, it requires a sort of willed incomprehension, and I think by now we need 
all the comprehension which we can manage to achieve if we're not going to ruin the world terminally.

It's very much more politically objectionable to draw on the aura of revolution for political purposes now than it was fifty years ago. Fifty years ago, there were many reasons for people to draw on it which weren't either disreputable, or stupid. I think that if you draw on it for those purposes today, what you're doing must be either objectionable or stupid.

BA: Finally, revisiting and rethinking Modern Revolutions now. If you were to say anything to readers about that book today, what would that be? Is there anything that you would say to a prospective reader?

JD: I think I would underline, more sharply than I did — than I have in print, in English anyway - , the thought that you must see revolution as a distinctive political phenomenon, and that you must see that it appears to be a bounded historical epoch, not actually a general structural potentiality of political existence. I would also probably say that I think the possibility of regime collapses proving to generate very dramatically different shapes of society afterward will depend on the creation of new, imaginatively compelling pictures of a collectively sharable kind of the form the transformation would need to take. I don't think there have been any examples of that so far, but I don't see why there couldn't be. It doesn't make any sense to think that you could predict that in a controlled way, so why pretend to be able to at all?

\section{References}

Dunn, John Montfort. 1972. Modern Revolutions: An Introduction to the Analysis of a Political 
Phenomenon. Cambridge: Cambridge University Press.

Dunn, John Montfort. 1989. Modern Revolutions: An Introduction to the Analysis of a Political Phenomenon. 2nd ed. Cambridge: Cambridge University Press.

Dunn, John Montfort. 2008. “Understanding Revolution.” In Revolution in the Making of the Modern World, ed. John Foran, David Lane, and Andreja Zivkovic, 17-26. London: Routledge.

Dunn, John Montfort. 2014. Revoluciones modernas: Introducción al análisis de un fenómeno politico. Trans. Santiago Díaz-Hellín Sepúlveda. Madrid: Tecnos.

Mayer, Arno. 2000. The Furies: Violence and Terror in the French and Russian Revolutions. Princeton: Princeton University Press.

McAdam, Doug, Sidney Tarrow, and Charles Tilly. 2001. Dynamics of Contention. Cambridge: Cambridge University Press.

McAdam, Doug, and Sidney Tarrow. 2011. "Introduction: Dynamics of Contention Ten Years On.” Mobilization 16 (1): 1-10.

Seven, Gulsen. 2012. “An Interview with John Dunn” International Political Anthropology 5(2): $179-196$

Skocpol, Theda. 1979. States and Social Revolutions. Cambridge: Cambridge University Press.

\section{Notes}

1 These are sometimes also called "color revolutions."

2 "There are rival political names for it, but it helps to think of it as being just one thing really," Dunn noted.

3 For further information on Dunn's concept of politics, and its link to his personal academic trajectory, see Seven (2012). 